\title{
Swallowing food without chewing; a simple way to reduce postprandial glycaemia
}

\author{
BY N. W. READ, I. MCL. WELCH, C. J. AUSTEN, C. BARNISH, \\ C. E. BARTLETT, A. J. BAXTER, G. BROWN, M. E. COMPTON, \\ K. E. HUME, I. STORIE AND J. WORLDING \\ Clinical Research Unit, H Floor, Royal Hallamshire Hospital, Sheffield S10 2JF
}

(Received 25 March 1985 - Accepted 2 August 1985)

\begin{abstract}
1. The degree to which disruption by mastication affects the glycaemic response to four different carbohydrate foods was investigated in healthy human volunteers; each food was eaten by six subjects.

2. Subjects ate meals of sweetcorn, white rice, diced apple or potato on two occasions; on one occasion they chewed the food thoroughly, on the other occasion they swallowed each mouthful without chewing it.

3. When the foods were chewed the postprandial blood glucose levels rose to levels which varied according to the food ingested.

4. Swallowing without chewing reduced the glycaemic response to each food, achieving a similar effect as administration of viscous polysaccharides or 'slow-release' carbohydrates.
\end{abstract}

Ingestion of foods which contain equivalent amounts of carbohydrate yield widely different effects on postprandial blood glucose levels and insulin release (Crapo et al. 1977, 1980; Jenkins et al. 1981), and it seems likely that the form in which food is ingested influences the rate of digestion and absorption of carbohydrates, the metabolic response to a meal and subsequent food intake. Carbohydrates in the form of sugars or potato starch are rapidly absorbed, yield high postprandial glycaemic and plasma insulin responses and may result in a rebound fall in blood glucose after a meal (Jenkins, 1983). Hyperinsulinaemia favours synthesis and deposition of fat, and is thought to lead to insulin resistance (Haber et al. 1977), while a rebound hypoglycaemia leads to the desire for more food soon after a carbohydrate-rich meal is eaten (Anand, 1974). Thus the introduction into the diet of meals that contain carbohydrates in a form that is absorbed slowly in the small intestine or not at all has been advocated as a simple means of preventing or treating diabetes mellitus or obesity (Crapo et al. 1977; Schauberger et al. 1977; Jenkins et al. 1981; Jenkins, 1983).

Viscous polysaccharides such as guar gum and pectin, that are resistant to the action of digestive enzymes, lower the postprandial glucose and insulin levels by delaying the delivery of food from the stomach (Leeds et al. 1978, 1981; Holt et al. 1979) into the small intestine and by reducing the mixing of intestinal contents (Blackburn et al. 1984).

Reductions in blood glucose and insulin can also be achieved by ingesting a high-legume diet, which contains carbohydrates that are digested slowly by pancreatic enzymes or not at all (Jenkins, 1983). Similar effects can be achieved by cooking starch for short periods of time (Collings et al. 1981) or presentation of food as large rather than small particles. O'Dea et al. $(1980,1981)$ demonstrated greater insulin and glucose responses when ground rice was ingested instead of whole rice; these effects were associated with increases in in vitro digestibility and may be explained by an increase in surface area available for attack by digestive enzymes. Haber et al. (1977) gave human volunteers whole apple, apple puree and apple juice containing equivalent amounts of carbohydrate. They observed that plasma insulin responses were much smaller after ingestion of whole apple than apple juice and that rebound hypogiycaemia was less after ingestion of whole apple, suggesting that the association of sugars with the unabsorbable components of the apple may delay sugar absorption. 
Chewing breaks food into smaller particles, enhances salivation and mixes it with salivary enzymes initiating hydrolysis of carbohydrate in the mouth and stomach. These effects would be expected to increase the glycaemic and insulaemic responses. Conversely, avoidance of chewing may be an alternative stratagem for delaying carbohydrate digestion and reducing blood glucose levels.

We have investigated whether the disruption of four different carbohydrate foods by mastication affects the glycaemic responses to these foods.

\section{MATERIALS AND METHODS}

\section{Subjects}

The effect of chewing on the blood glucose responses to four different carbohydrate foods (apple, sweetcorn, rice and potato) were investigated in paired experiments carried out in eight female and four male normal volunteers aged between 19 and 23 years, who had given their written informed consent for the study to be carried out. All subjects were within the normal range of body-weight for their height, age and sex. The protocol was approved by the Ethical Sub-committee of the Sheffield Area Health Authority (Teaching).

\section{Methods}

After fasting for at least $12 \mathrm{~h}$, subjects ingested a meal of either diced potato or apple (5-mm squares), or long grain white rice or sweetcorn. The peels and cores of the apples were removed and discarded before dicing. The portions of rice, sweetcorn and potato were designed so that the amount of available carbohydrate in each portion was $50 \mathrm{~g}$ according to approved food tables (Paul \& Southgate, 1978). It is acknowledged that some degree of variation from this value was inevitable due to the type of each food selected, however, subjects ate the same amount of food from the same source on both study days. The portions of apple contained $40 \mathrm{~g}$ carbohydrate because subjects found it difficult to ingest $50 \mathrm{~g}$. Rice and potato both contain carbohydrate in the form of starch. Sweetcorn contains more sugar than rice and potato and the carbohydrate is contained in a waxy coat which has to be disrupted before it can be digested. The majority of the carbohydrate in apple was in the form of fructose.

Each food was eaten by six people on two separate occasions. On one occasion they were instructed to take teaspoonfuls (approximately $7 \mathrm{~g}$ ) of the food and chew each teaspoonful thoroughly for $15 \mathrm{~s}$ before swallowing. On another occasion, each teaspoonful was swallowed without being chewed. The order of the two experiments was randomized. Care was taken to ensure that the rate of ingestion was identical in both experiments. Each pair of experiments was always carried out at the same time of the day and in female subjects the experiments were carried out at the same stage of the menstrual cycle in an attempt to control for possible menstrual variations in gastric emptying and small bowel transit (Wald et al. 1981). During all studies subjects remained seated on a comfortable upright chair, they were asked to refrain from any severe exercise and from drinking alcohol for at least $2 \mathrm{~d}$ before each study.

Samples of venous blood for glucose estimation were obtained from an intravenous catheter positioned in a forearm vein, these were collected before administration of the meal and at 15 -min intervals for $2.5 \mathrm{~h}$ after ingestion and the blood glucose concentration was determined using a glucose analyser (GM6; Analox, Eastleigh, Hampshire).

\section{Statistical analysis}

The statistical significance of the difference in results obtained when the four foods were chewed, compared with when they were swallowed without being chewed, was assessed using the Student's paired $t$ test. 
Sweetcorn

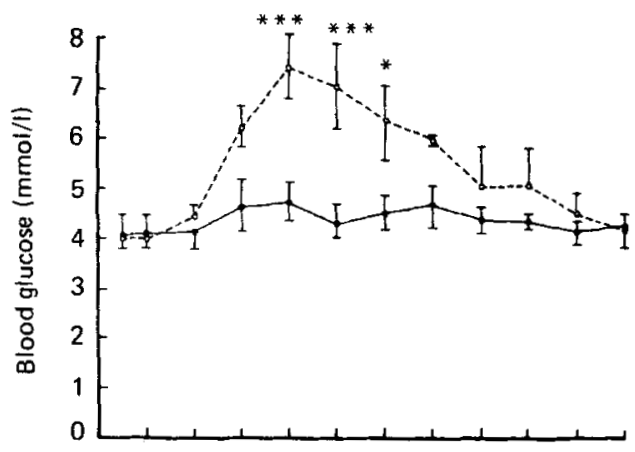

Rice

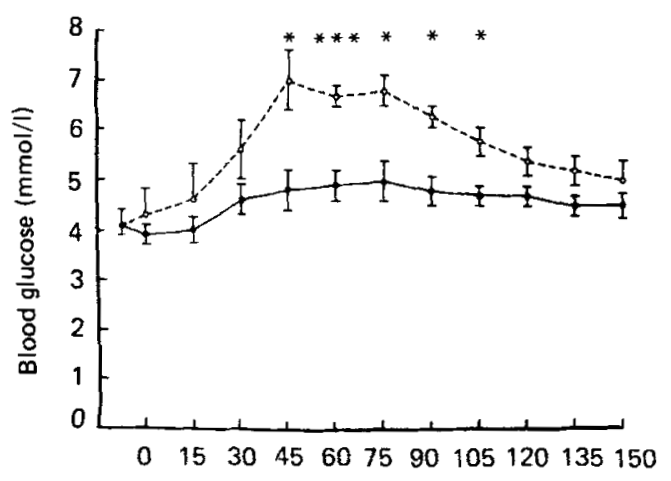

Potato

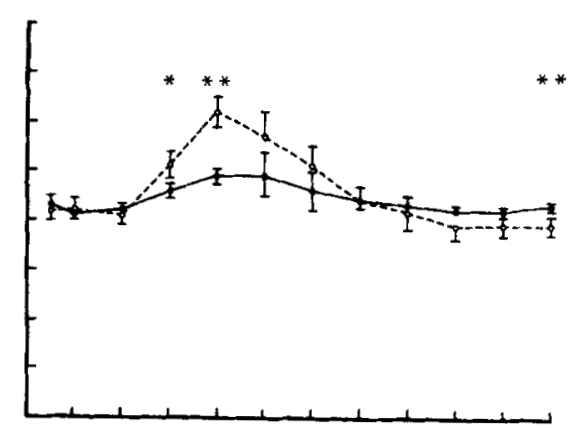

Apple

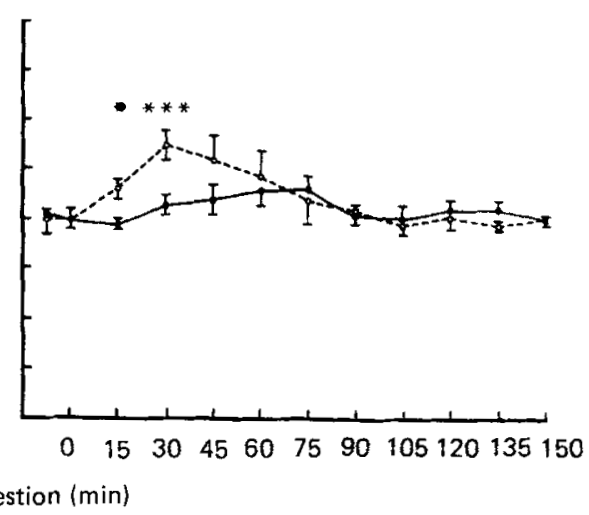

Fig. 1. The mean postprandial blood glucose responses following ingestion of four different foods by six normal subjects. (--), Responses when the foods were chewed thoroughly; (-), responses when the foods were swallowed whole. Mean values were significantly different (Student's paired $t$ test):

${ }^{*} P<0.05,{ }^{* *} P<0.01,{ }^{* * *} P<0.005$.

\section{RESULTS}

Subjects found the rice, potato and sweetcorn easy to swallow and each of these foods were ingested within $10 \mathrm{~min}$ during both control and test experiments. Apple was more difficult to swallow and subjects took up to $30 \mathrm{~min}$ to swallow the diced portions, though care was taken to match the rate of ingestion in the experiments when apple was chewed. No discomfort was experienced by any subject in any experiment.

When the food was thoroughly chewed, the postprandial glucose levels rose, though the extent to which they rose differed according to the food ingested (Fig. 1). Swallowing food without chewing significantly reduced the blood glucose responses to each food (Fig. 1). The peak glucose response and the areas under the blood glucose profiles in response to ingestion of rice, potato and sweetcorn, but not apple, were also significantly reduced when the subject swallowed these foods whole instead of chewing them thoroughly (Table 1). 
Table 1. The effect of chewing food on the glycaemic responses to four carbohydrate foods (Mean values with their standard errors for six observations)

\begin{tabular}{|c|c|c|c|c|c|c|}
\hline & \multicolumn{2}{|c|}{ Swallowing } & \multicolumn{2}{|c|}{ Chewing } & \multirow{2}{*}{$\begin{array}{l}\text { SED between } \\
\text { swallowing } \\
\text { and chewing }\end{array}$} & \multirow{2}{*}{$\begin{array}{c}\text { Student's } \\
\text { paired } t \text { test } \\
(P)\end{array}$} \\
\hline & Mean & $\mathrm{SE}$ & Mean & SE & & \\
\hline \multicolumn{7}{|c|}{$\begin{array}{l}\text { Peak plasma glucose concentration } \\
\text { (mmol/1) }\end{array}$} \\
\hline Sweetcorn & $5 \cdot 2$ & 0.4 & $8 \cdot 3$ & 0.7 & 0.42 & $<0.001$ \\
\hline Rice & $5 \cdot 3$ & 0.4 & $7 \cdot 1$ & $0 \cdot 5$ & 0.72 & $<0.05$ \\
\hline Potato & $5 \cdot 2$ & $0 \cdot 3$ & $6 \cdot 3$ & $0 \cdot 3$ & $0 \cdot 28$ & $<0.02$ \\
\hline Apple & 4.9 & $0 \cdot 3$ & 5.7 & $0 \cdot 4$ & 0.19 & NS \\
\hline \multicolumn{7}{|c|}{$\begin{array}{c}\text { Area under } 2.5 \mathrm{~h} \text { plasma glucose } \\
\text { profile }(\mathrm{mmol} \times \mathrm{min})\end{array}$} \\
\hline Sweetcorn & 71 & 30 & 289 & 78 & $17 \cdot 7$ & $<0.025$ \\
\hline Rice & 86 & 34 & 244 & 37 & $13 \cdot 8$ & $<0.05$ \\
\hline Potato & 45 & 19 & 94 & 26 & $4 \cdot 4$ & $<0.05$ \\
\hline Apple & 49 & 22 & 90 & 34 & $4 \cdot 3$ & NS \\
\hline
\end{tabular}

SED, standard error of difference; NS, not significant.

\section{DISCUSSION}

The present study has shown that swallowing diced portions of carbohydrate foods yields a lower glycaemic response than chewing the same foods thoroughly. The response to sweetcorn was greater than that to the others, probably because sweetcorn is retained in a waxy hull, which can only be disrupted by mastication. The effect of chewing was least with apple, partly because only $40 \mathrm{~g}$ carbohydrate could be ingested in the form of apple but probably also because apple contains carbohydrate in the form of fructose, which yields a lower glycaemic response than an equivalent amount of glucose (Bohanum et al. 1978).

Chewing could increase the digestibility and absorption of carbohydrate in several ways; the reduction in particle size would enhance the delivery of food from the stomach to the small intestine (Meyer et al. 1979; Minami \& McCallum, 1984); the larger surface area of masticated food increases access to pancreatic enzymes; enhancement of salivation associated with chewing would increase digestion of food in the mouth and stomach. Whatever the mechanism, the experiment underlines the importance of the form in which food is delivered to the small intestine in determining the glycaemic response.

Whether it would ever be practicable to advise patients with diabetes or obesity to reduce mastication as a means of controlling blood glucose is questionable. Swallowing food in diced portions would certainly reduce the pleasure of eating and could be dangerous if patients had any history of oesophagitis or stricture. Such advice also runs contrary to the stratagem used in some slimmers' clinics where patients are advised to chew their food thoroughly in order to reduce the rate of ingestion. In spite of these considerations, it could be argued that such a simple device could allow patients to reduce blood glucose levels without fundamentally altering their diets and may thus prove more acceptable than the ingestion of viscous polysaccharides or beans, which can cause abdominal discomfort, distension and flatulence. 


\section{REFEREN CES}

Anand, B. K. (1974). In Obesity Symposium, pp. 116-145 [W. Z. Burland, P. D. Samuel and J. Yudkin, editors]. Edinburgh: Churchill Livingstone.

Blackburn, N. A., Redfern, J. S., Jarjis, H., Holgate, A. M., Hanning, I., Scarpello, J. H., Johnson, I. T. \& Read, N. W. (1984). Clinical Science 66, 329-336.

Bohanum, I. V. V., Karam, J. H. \& Forsham, P. H. (1978). Diabetes 27, 438.

Collings, P., Williams, C. \& McDonald, I. (1981). British Medical Journal 282, 1032.

Crapo, P. A., Kolterman, O. G., Waldeck, N., Reaven, G. M. \& Olefsky, J. M. (1980). American Journal of Clinical Nutrition 33, 1723-1728.

Crapo, P. A., Reaven, G. \& Olefsky, J. (1977). Diabetes 26, 1178-1183.

Haber, G. B., Heaton, K. W., Murphy, D. \& Burroughs, L. F. (1977). Lancet ii, 679-682.

Holt, S., Heading, R. C., Carter, D. C., Prescott, L. F. \& Tothill, P. (1979). Lancet i, 636-639.

Jenkins, D. J. A. (1983). In Delaying Absorption as a Therapeutic Principle in Metabolic Diseases, pp. 45-56. [W. Creutzfeldt and U. R. Folsch, editors]. Stuttgart: Georg Thieme Verlag.

Jenkins, D. J. A., Thomas, D. M., Wolever, M. S., Taylor, R. H., Barker, H., Fielden, H., Baldwin, J. M., Bowling, A. C., Newman, H. C., Jenkins, A. L. \& Goff, D. V. (1981). American Journal of Clinical Nutrition 34, 362-366.

Leeds, A. R., Ralphs, D. N., Baulas, P., Ebied, F., Metz, G. L., Dilawari, J., Elliot, A. \& Jenkins, D. J. A. (1978). Proceedings of the Nutrition Society 37, $23 \mathrm{~A}$.

Leeds, A. R., Ralphs, D. N., Ebied, F., Metz, G. \& Dilawari, J. (1981). Lancet i, 1075-1078.

Meyer, J. H., Thomson, J. B., Cohen, M. B., Shadchehr, A. \& Mandiola, S. A. (1979). Gastroenterology 76, 804-813.

Minami, H. \& McCallum, R. W. (1984). Gastroenterology 86, 1592-1610.

O'Dea, K., Nestel, P. J. \& Antonoff, L. (1980). American Journal of Clinical Nutrition 33, 760-765.

O'Dea, K., Snow, P. \& Nestel, P. (1981). American Journal of Clinical Nutrition 34, 1991-1993.

Paul, A. A. \& Southgate, D. A. T. (1978). McCance and Widdowson's The Composition of Foods. London: H.M. Stationery Office.

Schauberger, G., Brink, U. C., Guldner, G., Spaethe, R., Niklas, L. \& Otto, H. (1977). Diabetes $26,246$.

Wald, A., Van Thiel, D. H., Hoechstetter, L., Gavaler, J. S., Egler, K. M., Verm, R., Scott, L. \& Lester, R. (1981). Gastroenterology 80, 1497-1500. 